\title{
An Exploration of the Reproductive Health Concerns in Women with Systemic Lupus Erythematosus
}

\author{
Shimol J B* \\ Department of Medicine, E. Wolfson Medical Center, \\ Holon, Israel \\ *Corresponding author: J ennifer Ben Shimol, \\ Department of Medicine, E. Wolfson Medical Center, \\ Holon, Israel
}

Received: May 10, 2021; Accepted: J une 10, 2021; Published: June 17, 2021

\section{Editorial}

Systemic Lupus Erythematosus (SLE) is more frequent in women, with a female-to-male ratio ranging from 2-6:1 prior to puberty and 3-8:1 following menopause up to 8-15:1 during their fertile years [1]. SLE commonly begins when women are in their 20s, during the prime of their child-bearing years when they are often beginning to plan their families [2], and may have enormous impact on their childrearing.

Although rates of infertility are not felt to be elevated among women with SLE, secondary amenorrhea has been identified in $13-17 \%$ of women with SLE who are naïve to cyclophosphamide, compared with a prevalence $1-5 \%$ in a healthy population [3]. One reason may be related lower levels of anti-Mullerian hormone [4] and higher levels of elevated anti-corpus luteum antibody levels in female patients with SLE [5].

According to one study, 64\% women with SLE had fewer children than originally planned. This is likely a result of many factors including disease and medication impact on fertility and fear of disease flare-up with pregnancy. Moreover, many socioeconomic challenges accompany the disease, particularly concerns about the impact of SLE on child welfare and family life, a feature shared by many other chronic illnesses. One study reported that patients with SLE who chose to have less children than they had previously desired described concerns about inability to care for a child, damage from medications, and genetic transmission of their disease leading to the decision to pursue fewer pregnancies [6,7]. Anxieties regarding transmission and impaired ability to take care of children are among the primary worries of patients with lupus [8]. Nevertheless, this generally does not reflect a major concern of medical practitioners, leading to gaps in communication and discordant goals of care [9].

Despite intact fertility among SLE patients, there is morbidity associated with pregnancy. One study of 13,555 participants illustrated a maternal mortality 20 -fold higher among women with SLE compared with healthy age-matched controls [10]. The rate of miscarriage is reported as $21.2 \%$ compared with $14 \%$ in a normal population. While the percentage of live births ranges from 85 to 90 , pregnancy is considered a high-risk situation for female SLE patients [11]. Rate of stillbirth is 5 to 10 fold higher in patients with SLE than in the general population [12]. Preeclampsia is more common in
SLE and may occur in up to $20 \%$ of lupus related pregnancies [13]. There is also increased risk for fetal morbidity, particularly preterm birth (12\%) among SLE pregnancies compared with $4 \%$ in controls), intrauterine growth restriction, and neonatal lupus $[11,14]$. One third of pregnancies end in caesarian section [15].

Pregnancy morbidity is most strongly associated with increased disease activity in the six to 12 months prior to and during pregnancy, especially in cases with renal involvement $[16,17]$. Other risk factors in pregnancy include presence of hypocomplementemia, elevated levels of anti-DNA antibodies, antiphospholipid antibodies, and thrombocytopenia [18,19]. Moreover, pregnancy and the period immediate following delivery is a well-known time for lupus flare-ups [20]. While the hormonal influence on pregnancy is not fully understood due to the complicated interwoven hormonalinflammatory pathways, a disruption in the balance of Treg's and Th17 helper cells and elevated IFN- $\gamma$ appear to be players in generating poorer pregnancy outcomes [21,22].

Other maternal complications are related to the hypercoagulability of pregnancy augmented to the increased coagulation risk in SLE in general. During pregnancy, the risk of venous thromboembolism in patients with SLE is 62 out of 10,000 compared with 7.22 of 10,000 in the general population. Moreover, the risk of pulmonary embolism is significantly increased with an odds ratio of 9.76 [23]. In addition, the risk for stroke is 6.5 -fold higher than that of healthy pregnant women [24].

In addition to the effect that SLE itself may impose on pregnancy and delivery, certain related medications are teratogenic. Moreover, cyclophosphamide can actually impair fertility, primarily by causing premature ovarian failure $[25,26]$. Accordingly, providers are advised to offer child-bearing women $\mathrm{GnRH}$ analogue therapy prior to initiation of cyclophosphamide [27]. Furthermore, observational studies have shown that most assisted reproductive techniques are safe and equally effective among women with SLE. There are no official guidelines regarding any specific protocol to be used among SLE patients aside from antithrombotic prophylaxis among women with antiphospholipid antibodies [28,29].

Among those patients who seek contraception, most options are available to women with SLE. Women with antiphospholipid lipid antibodies, even without a history of clotting or obstetric complication, and women with additional clotting risk factors including migraines and smoking, should be advised against use of combined hormones. However, aside from this advisement, most other contraceptive methods have proven to be safe in patients with SLE [30].

Nonetheless, despite vigorous research demonstrated the safety and benefits of contraception in patients with SLE, effective methods of birth control are widely underused. One study reported 55\% of SLE
Austin J Womens Health - Volume 8 Issue 2 - 2021

Submit your Manuscript | www.austinpublishinggroup.com

Shimol. (c) All rights are reserved
Citation: Shimol JB. An Exploration of the Reproductive Health Concerns in Women with Systemic Lupus Erythematosus. Austin J Womens Health. 2021; 8(2): 1053. 
patients had unprotected sex occasionally and another $23 \%$ engaged in unprotected sex most of the time [31]. Another glaring study found that $55 \%$ of patients with SLE using contraceptives regularly were using less-effective barrier methods only, even while on teratogenic medications [32]. These findings highlight the immense obstacle that patients with SLE face in receiving comprehensive care that meets their needs during their fertile years.

Over the last decade, there is a growing understanding of the importance of early, open, and continual discussions on the topic of family planning between providers and patients. The ACR and EULAR have devised recommendations for providers to help stratify patients and offer appropriate counseling regarding contraception, conception, and assisted reproduction [33,34]. Despite the progress that has been achieved, future studies are warranted to determine how to best approach these patients and best counsel them through the complicated, interrelated pyschologic and medical issues that accompany SLE during the child-bearing stage.

\section{References}

1. Cattalini M, Soliani M, Caparello MC, Cimaz R. Sex differences in pediatric rheumatology. Clin Rev Allergy Immunol. 2017; 56: 293-307.

2. Rees F, Doherty M, Grainge MJ, Lanyon P, Zhang W. The worldwide incidence and prevalence of systemic lupus erythematosus: a systematic review of epidemiological studies. Rheumatology. 2017; 56: 1945-1961.

3. Knight JH, Howards PP, Spencer JB, et al. Characteristics related to early secondary amenorrhoea and pregnancy among women diagnosed with systemic lupus erythematosus: an analysis using the GOAL study. Lupus Science \& Medicine. 2016; 3: e000139.

4. Ma W, Zhan Z, Liang $X$, et al. Subclinical impairment of ovarian reserve in systemic lupus erythematosus patients with normal menstruation not using alkylating therapy. J Womens Health. 2013; 22: 1023-1027.

5. Pasoto SG, Viana VS, Mendonca BB, et al. Anti-corpus luteum antibody: a novel serological marker for ovarian dysfunction in systemic lupus erythematosus? J Rheumatol. 1999; 26: 1087-1093.

6. Clowse ME, Chakravarty E, Costenbader KH, Chambers C, Michaud K. Effects of infertility, pregnancy loss, and patient concerns on family size of women with rheumatoid arthritis and systemic lupus erythematosus. Arthritis Care Res. 2012; 64: 668-674.

7. Wirtberg I, Moller A, Hogstrom L, Tronstad SE, Lalos A. Life 20 years after unsuccessful infertility treatment. Hum Reprod. 2007; 22: 598-604.

8. Farinha F, Freitas F, Agueda A, Cunha I, Barcelos A. Concerns of patients with systemic lupus erythematosus and adherence to therapy - a qualitative study. Patient Prefer Adher. 2017; 11: 1213-1219.

9. Golder V, Ooi JJY, Antony AS, Ko T, Morton S, Kandane-Rathnayake R, et al. Discordance of patient and physician health status concerns in systemic lupus erythematosus. Lupus. 2018; 27: 501-506.

10. Clowse ME, Jamison M, Myers $E$, James $A H$. A national study of the complications of lupus in pregnancy. Am J Obstet Gynecol. 2008; 199: 127.

11. Petri M, Allbritton J. Fetal outcome of lupus pregnancy: a retrospective casecontrol study of the Hopkins Lupus Cohort. J Rheumatol. 1993; 20: 650-656.

12. Smyth A, Oliveira GH, Lahr BD, Bailey KR, Norby SM, Garovic VD. A systematic review and meta-analysis of pregnancy outcomes in patients with systemic lupus erythematosus and lupus nephritis. Clin J Am Soc Nephrol. 2010; 5: 2060-2068.

13. Abalos E, Cuesta C, Grosso AL, Chou D, Say L. Global and regional estimates of preeclampsia and eclampsia: a systematic review. Eur J Obste Gynecol Reprod Biol. 2013; 170: 1.

14. Wei S, Lai K, Yang Z, Zeng K. Systemic lupus erythematosus and risk of preterm birth: a systematic review and meta-analysis of observational studies. Lupus. 2017; 26: 563-571.

15. MEB Clowse. "Lupus activity in pregnancy". Rheumatic Disease Clinics of North America. 2007; 33: 237-252.

16. Clowse ME, Magder LS, Witter F, Petri M. The impact of increased lupus activity on obstetric outcomes. Arthritis Rheum. 2005; 52: 514-521.

17. Bramham K, Hunt BJ, Bewley S, et al. Pregnancy outcomes in systemic lupus erythematosus with and without previous nephritis. J Rheumatol. 2011; 38 : 1906-1913.

18. MEB Clowse, LS Magder, F Witter and M Petri. "Early risk factors for pregnancy loss in lupus". Obstetrics and Gynecology. 2006; 107: 293-299.

19. K-LWong, F-Y Chan and C-P Lee. "Outcome of pregnancy in patients with systemic lupus erythematosus. A prospective study". Archives of Internal Medicine. 1991; 151: 269-273.

20. Lateef A, Petri M. Systemic Lupus Erythematosus and Pregnancy. Rheumatic Disease Clinics of North America. 2017; 43: 215-226.

21. C Tower, I Crocker, D Chirico, P Baker, and I Bruce. "SLE and pregnancy: the potential role for regulatory T cells". Nature Reviews Rheumatology. 2011; 7: $124-128$.

22. D Andrade, M Kim, LP Blanco, et al. "Interferon- $\square$ and angiogenic dysregulation in pregnant lupus patients destined for preeclampsia". Arthritis \& Rheumatology. 2015; 67: 977-987

23. Bleau N, Patenaude V, Abenhaim HA. Risk of Venous Thromboembolic Events in Pregnant Patients with Autoimmune Diseases: A Population-Based Study. Clin Appl Thromb Hemost. 2016; 22: 285-291.

24. Clowse $M E$, Jamison $M$, Myers $E$, James $A H$. A national study of the complications of lupus in pregnancy. Am J Obstet Gynecol. 2008; 199: 127. e1-127.e1276

25. Østensen M, Förger F. How safe are anti-rheumatic drugs during pregnancy? Curr Opin Pharmacol. 2013; 13: 470-475.

26. loannidis JP, Katsifis GE, Tzioufas AG, et al. Predictors of sustained amenorrhea from pulsed intravenous cyclophosphamide in premenopausal women with systemic lupus erythematosus. J Rheumatol. 2002; 29: 2129 2135 .

27. Elizur SE, Chian RC, Pineau CA, et al. Fertility preservation treatment for young women with autoimmune diseases facing treatment with gonadotoxic agents. Rheumatology (Oxford). 2008; 47: 1506-1509.

28. Ragab A, Barakat R, Ragheb M, et al. Sub fertility treatment in women with systemic lupus erythematosus. J Obstet Gynaecol. 2012; 32: 569-571.

29. Orquevaux P, Masseau A, Le Guern V, et al. [In vitro fertilization and systemic lupus erythematosus or antiphospholipid syndrome: an update]. Rev Med Interne. 2015; 36: 154-158.

30. Sánchez-Guerrero J, Uribe AG, Jiménez-Santana L, et al. A trial of contraceptive methods in women with systemic lupus erythematosus. N Engl J Med. 2005; 353: 2539-2549.

31. J Yazdany, L Trupin, R Kaiser, et al. "Contraceptive counseling and use among women with systemic lupus erythematosus: a gap in health care quality"? Arthritis Care and Research. 2011; 63: 358-365.

32. EB Schwarz and S Manzi. "Risk of unintended pregnancy among women with systemic lupus erythematosus" Arthritis Care \& Research. 2008; 59: 863-866.

33. Kavanaugh A, Cush JJ, Ahmed MS, et al. Proceedings from the American College of Rheumatology Reproductive Health Summit: the management of fertility, pregnancy, and lactation in women with autoimmune and systemic inflammatory diseases. Arthritis Care Res (Hoboken). 2015; 67: 313-325.

34. Andreoli L, et al. EULAR recommendations for women's health and the management of family planning, assisted reproduction, pregnancy and menopause in patients with systemic lupus erythematosus and/or antiphospholipid syndrome. Ann Rheum Dis. 2017; 76: 476-485. 